Revista de Derecho

\title{
Las mujeres víctimas de trata de personas con fines de explotación sexual. Los nexos con el patriarcado y un negocio dentro del capitalismo
}

Women as Victims of Sexual Exploitation because of Human Trafficking, its Relationship with Patriarchalism and a Business Inside of Capitalist System

Evelyn Soledad Zurita Cajas

Investigadora independiente

Quito, Ecuador

eviezurita@gmail.com

ORCID: 0000-0002-1702-5744

Artículo de investigación

DOI: https://doi.org/10.32719/26312484.2022.37.3

Fecha de recepción: 30 de junio de 2021

Fecha de revisión: 2 de agosto de 2021

Fecha de aceptación: 15 de septiembre de 2021

Fecha de publicación: 3 de enero de 2022 


\section{RESUMEN}

El presente artículo hace una aproximación hacia la realidad que viven las mujeres víctimas de trata de personas con fines de explotación sexual, desde una perspectiva sociológica y jurídica que va más allá de la visión sancionatoria ejercida por los estados. Abordar la trata de personas únicamente enfocada en la restricción, el control y la expansión del poder punitivo del Estado para localizar y perseguir a los tratantes de personas solo ha generado la revictimización de los cuerpos explotados con la trata.

En este contexto, estudiarla desde otra esfera interdisciplinaria permite visibilizar la trata como una práctica generada por el patriarcalismo y como un negocio impulsado por los estados y las empresas nacionales e internacionales que activan los flujos comerciales y operan dentro del sistema capitalista.

Por ello, este trabajo realiza una breve conceptualización de la trata de personas, describe las nuevas modalidades bajo las cuales opera la trata de personas que les ha permitido esconderse de los controles impulsados por los estados, en donde se identifica que los tratantes han generado mínimos de legalidad dentro y fuera de las fronteras de los países para poder operar con regularidad. Finalmente concluye puntualizando y mostrando la trata de personas como una dinámica violenta y eminentemente patriarcal, en donde se destacan cifras que muestran que el colectivo social más vulnerable explotado por la trata son las mujeres.

PALABRAS CLAVE: trata de personas; víctimas; explotación sexual; esclavitud humana; violencia; patriarcalismo; sistema capitalista; derechos humanos.

\section{ABSTRACT}

The main purpose of this article is making an approximation to experiences lived women who were victims by Human Trafficking and sexual exploitation from a sociological and legal perspective putting aside the penalizing vision which states apply frequently related with Human Trafficking victims. Due to restriction, control and expansion of punitive power from states to locate and prosecute traffickers, Human Trafficking victims have been forgotten subjects of law and their status as victims have been greatly emphasized.

That is why it is necessary to study Human Trafficking from another sphere, as a practice generated by patriarchalism and as a business promoted many times by states and national and international companies which operate within the capitalist system. In this sense, this text begins with a general conceptualization about human trafficking.

As a second aspect, it shows the new and recent methods in which human trafficking operates hiding from the majority of controls and inspections promoted by the states, where traffickers have generated minimum legality conditions within 
and outside of many countries. Finally, it concludes positioning Human Trafficking as a violent and patriarchal social practice.

KEYWORDS: Human trafficking; victims; sexual exploitation; human slavery; violence; patriarchalism; capitalist system; human rights.

\section{DEFINICIONES Y ELEMENTOS DE LA TRATA DE PERSONAS}

E n el marco de la firma de la Convención de las Naciones Unidas contra la delincuencia organizada transnacional de 2000, nace el primer protocolo para prevenir, reprimir y sancionar la trata de personas, especialmente mujeres y niños contra la delincuencia organizada transnacional, denominado también Protocolo de Palermo que entró en vigor el 25 de diciembre de 2003. El artículo 3 del Protocolo de Palermo define a la trata de personas como:

la captación, el transporte, el traslado, la acogida o la recepción de personas, recurriendo a la amenaza o al uso de la fuerza u otras formas de coacción, al rapto, al fraude, al engaño, al abuso de poder o de una situación de vulnerabilidad o a la concesión o recepción de pagos o beneficios para obtener el consentimiento de una persona que tenga autoridad sobre otra, con fines de explotación. ${ }^{1}$

La Convención Americana sobre Derechos Humanos, dentro del derecho a la integridad personal en su artículo 5 señala que todas las personas tienen derecho a que se respete su integridad física, psíquica y moral. ${ }^{2}$ En relación a la prohibición de tortura y tratos crueles manifiesta: "Nadie debe ser sometido a torturas ni a penas o tratos crueles, inhumanos o degradantes. Toda persona privada de libertad será tratada con el respeto debido a la dignidad inherente al ser humano". 3

El número 4 del artículo 46 de la Constitución del Ecuador señala que el Estado ecuatoriano brindará protección y atención especial contra "todo tipo de violencia,

1. Naciones Unidas, Convención de las Naciones Unidas contra la delincuencia organizada transnacional y sus protocolos, 2004, 96, art. 3.

2. Costa Rica, Convención Americana sobre Derechos Humanos, Convenio 36 de la Organización de Estados Americanos, 22 de noviembre de 1969, art. 5.1.

3. Ibíd., art. 5.2. 
maltrato, explotación sexual o de cualquier otra índole, o contra la negligencia que provoque tales situaciones". ${ }^{4}$

El Código Orgánico Integral Penal define al delito de trata de personas como:

Toda persona que capte, transporte, traslade, retenga o reciba; en el país, desde o hacia otros países con fines de explotación; para lo cual un tercero recurre a la amenaza, uso de la fuerza u otras formas de coacción, al rapto, al fraude, al engaño, al abuso de poder o de una situación de vulnerabilidad, a la concesión o aceptación de pagos o beneficios, constituye delito de trata de personas. ${ }^{5}$

En este sentido, en el mismo artículo y cuerpo normativo, se indica que: "la explotación sexual de personas incluida la prostitución forzada, el turismo sexual y la pornografía infantill" serán formas de explotación en el contexto de la trata de personas.

Por su parte, la Ley Orgánica de Movilidad Humana de la legislación ecuatoriana señala que se considera una víctima de trata de personas a:

Quien haya sido objeto de captación, transporte, traslado, retención o recepción; en el país, desde o hacia otros países con fines de explotación; para lo cual un tercero recurre a la amenaza, uso de la fuerza u otras formas de coacción, al rapto, al fraude, al engaño, al abuso de poder o de una situación de vulnerabilidad, a la concesión o aceptación de pagos o beneficios. ${ }^{7}$

Para que pueda configurarse la trata de personas, según la información proporcionada por la Organización para la Seguridad y la Cooperación en Europa (OSCE) se deben observar principalmente tres componentes: 1) El acto: determina lo que se hace, es decir el reclutamiento, transporte, traslado, acogida o recepción de personas. 2) Los medios: determina cómo se hace, es decir: este reclutamiento, transporte, traslado, acogida o recepción de personas tiene que darse en el contexto de amenaza o uso de la fuerza u otras formas de coacción, al rapto, al fraude, al engaño, al abuso de poder o de una situación de vulnerabilidad o de dar o recibir pagos o beneficios para lograr el consentimiento de una persona que tenga autoridad sobre otra.

Es importante entonces, identificar el tercer elemento de esta dinámica delictiva que es el fin, que justifica el por qué se realiza la trata de personas. Este fin es la explotación y surge en el marco de la prostitución forzada y otras formas de explotación

4. Ecuador, Constitución de la República del Ecuador, Registro Oficial 449, 20 de octubre de 2008, art. 46.4.

5. Ecuador, Código Orgánico Integral Penal, Registro Oficial 180, 10 de febrero de 2014, art. 91.

6. Ibíd., art. 91.2.

7. Ecuador, Ley Orgánica de Movilidad Humana, Registro Oficial 938, 6 de febrero de 2017, art. 117. 
sexual, trabajo o servicios forzados, esclavitud humana o prácticas análogas a la esclavitud incluyendo extracción y tráfico de órganos. ${ }^{8}$

\section{TRATANTES INDIVIDUALES Y REDES INTERNACIONALES DE TRATA}

Para comprender quiénes están detrás de la trata de personas se debe examinar la estructura organizativa de los participantes y actores de la trata de personas. Inicialmente, se puede hacer una distinción entre tratantes criminales y tratantes no criminales que operan de forma individual, mientras que también existen tratantes que operan como una pieza parte de una red u organización criminal internacional de trata de personas cumpliendo un rol determinado, y finalmente, están los estados como responsables y generadores de violencia.

Los tratantes criminales son aquellos que están profundamente inmersos en un estilo de vida criminal y pueden estar involucrados en otros delitos, mientras que los tratantes considerados no criminales podrían considerarse terceras personas o víctimas que han sido forzadas a reclutar a otros o personas que no están involucradas en ningún delito, pero que están actuando en el contexto de trata y por ende están vinculadas a la explotación personas. ${ }^{9}$

Las redes internacionales de trata de personas se constituyen como un grupo de personas con intereses y aspiraciones similares que interactúan y permanecen en contacto informal para la asistencia o apoyo mutuo. A menudo se caracterizan por su especialización, flexibilidad y segmentación. En estas redes se distinguen: en primer lugar, las redes de delincuentes organizados que están relacionadas con la trata interna, también están vinculados a la trata internacional pero en pequeña escala. Generalmente se identifican ciertos perfiles de tratantes como empresarios criminales que operan en conexión con empresas asociadas pero también se han identificado empresarios independientes.

En segundo lugar, se ubican las redes internacionales altamente estructuradas. Estas redes criminales son muy flexibles y pueden estar compuestas por familiares y amigos. Este nivel de organización requiere a grupos más grandes y más sofisticados que están involucrados en la constante provisión de víctimas para los mercados es-

8. Alexis A. Aronowitz, Gerda Theuermann y Elena Tyurykanova, Analysing the Business Model of Trafficking in Human Beings to Better Prevent the Crime (Vienna: OSCE Office to the Special Representative and Co-ordinator for Combating Trafficking in Human Beings, 2010), 9.

9. Ibíd., 22-3. 
pecializados en la explotación sexual en países extranjeros, en donde venden de sus víctimas a propietarios de burdeles en el país de destino, incluso organizan la rotación de víctimas entre ciudades y países, debido a que el mercado del sexo constantemente requiere cuerpos nuevos y caras nuevas. ${ }^{10}$

Las organizaciones criminales altamente estructuradas controlan todo el proceso de trata desde el reclutamiento, el transporte, la explotación e incluso la eliminación de las víctimas. Este grupo maneja el conjunto completo de servicios a lo largo de toda la cadena de la trata. Están relacionados la falsificación de documentos, por ello se ha identificado que estas redes mantienen vínculos incluso con funcionarios gubernamentales corruptos o que generan presión hasta corromperlos cuando sea necesario.

\section{PERFILES Y ROLES DE LOS TRATANTES}

Como se ha venido tejiendo en líneas anteriores, las redes de trata de personas operan en diferentes escenarios y su flexibilidad les ha permitido expandirse en diferentes esferas nacionales e internacionales e incluso mantener nexos con funcionarios estatales. En esta secuencia operativa se determina que los miembros de estas redes se especializan en ciertas operaciones, es decir, en el reclutamiento, el suministro de un lugar para mantener a las víctimas ocultas, la elaboración de documentos falsos, el transporte de víctimas hacia y desde su trabajo, la explotación directa y rotación de víctimas a diferentes destinos internos e internacionales.

Dentro de este flujo operativo se destacan los siguientes roles: 1) Los inversores: financian supervisan toda la operación, son personas poco conocidas y están resguardadas por una estructura piramidal organizativa que protege su anonimato, incluso pueden estar separados de la organización; ${ }^{11} 2$ 2) Los reclutadores: buscan potenciales víctimas nacionales o extranjeras, inclusive migrantes porque no poseen una condición legal en el país donde se encuentran y persuaden a las víctimas hasta asegurar su compromiso financiero; ${ }^{12}$ 3) Los transportistas: conectan y ayudan a víctimas a salir de su país de origen. Este traslado es por tierra, mar o aire; 4) Los funcionarios públicos corruptos: estos funcionarios facilitan la obtención de documentos que cuentan con toda la legalidad para garantizar el traslado de las víctimas. Están vinculados con la recepción de sobornos y encubren cualquier investigación estatal, incluso su alcan-

10. Women's Link Worldwide, Victimas de trata en América Latina. Entre la desprotección e indiferencia, Informe n. ${ }^{\circ} 7$ (Madrid, 2017), https://bit.ly/3zlkJU2.

11. Aronowitz, Theuermann y Tyurykanova, Analysing the Business Model of Trafficking in Human Beings to Better Prevent the Crime, 24.

12. Ibíd. 
ce puede llegar a obstruir cualquier proceso penal iniciado o que esté por iniciarse; ${ }^{13}$ 5) Los informantes: recogen información sobre la vigilancia realizada en las fronteras de los países, los procedimientos de inmigración, el tránsito de personas y los sistemas de asilo y refugio $;{ }^{14} 6$ ) Los guías y tripulantes: trasladan a las víctimas de un punto al otro (trata interna o externa) ${ }^{15}$ 7) Los encargados: son los responsables de vigilar al personal parte de la red, de mantener el orden y de controlar a las víctimas; ${ }^{16} 8$ ) Los cobradores: crean las tarifas y cobran las deudas a las víctimas; 9) Los lavadores de dinero: cambian el producto del delito, disfrazan su origen a través de una serie de transacciones invirtiéndolas en negocios lícitos; ${ }^{17} \mathrm{y}$, finalmente; 10) El personal de apoyo: son personas locales que colaboran en los puntos de tránsito y quienes que proporcionan alojamiento temporal y otras asistencias que puedan requerirse. ${ }^{18}$

\section{DESPOJO Y APROPIACIÓN DE LOS CUERPOS DE LAS VÍCTIMAS DE TRATA}

Un cuerpo de una víctima de trata es clasificado como un cuerpo desechable, despojado y cosificado por el sistema; por ende, es comercializado. El sistema capitalista también ha colocado los derechos que tienen unos cuerpos sobre otros. De la misma forma, existen cuerpos que no pueden ejercer de forma directa e inmediata sus derechos. Por ejemplo, existen derechos como: el derecho a la vida, a la libertad personal y el derecho a la protección integral que las víctimas de trata pierden desde su captación y que probablemente sean irreparables. En esta dinámica capitalista, la vida se ha convertido en un privilegio para quienes gozan de esta libertad a diferencia de quienes no la poseen.

Giorgio Agamben hace un análisis del valor de vida y en función de qué parámetros se mide ese valor. La vida de unos cuerpos es considerada una virtud innata a los seres humanos y el cese de ella, la muerte, es la ausencia de la vida; sin embargo, ¿qué sucede con los cuerpos que no poseen este privilegio?

Agamben nos invita entonces a analizar el término humanidad. ¿Por qué esta humanidad (que deberíamos ser todos los cuerpos) alcanza para unos y para otros no? Al desconocer los derechos laborales, a la salud, a la alimentación, a la libre movilidad,

\footnotetext{
13. Ibíd., 25.

14. Ibíd.

15. Ibíd.

16. Ibíd.

17. Ibíd.

18. Ibíd.
} 
etc., de los migrantes, se les está quitando esta categoría de sujetos de derechos. ¿Acaso se está cuestionando su humanidad? Cuando un migrante considerado irregular muere en territorio extranjero, ¿tiene las mismas condiciones que un nacional?

La respuesta es no; probablemente ese extranjero que se encuentra solo, lejos de su familia, que nunca tuvo derechos laborales, que nunca tuvo acceso a la salud, para quien su día a día siempre estuvo cargado de explotación, desnutrición y constante violencia, los derechos son solo relatos. La muerte como ausencia de la vida, dice Agamben, es un privilegio para quienes son considerados seres humanos, entonces estos otros cuerpos son solo cadáveres. ${ }^{19}$ Estos "no-hombres" a quienes ni la dignidad ni los derechos les ha alcanzado ni siquiera podrían tener una muerte digna.

Reconocer el derecho a la vida de estos cuerpos implicaría reconocer su muerte; por ende, el Estado en donde fallecen las víctimas tendría que activar todos los mecanismos normativos e institucionales para darle una muerte digna a estos cuerpos, lo que comprendería: activar los recursos que fueran necesarios para repatriar los cadáveres, contactar a sus familiares, movilizar a las misiones diplomáticas, otorgarles incentivos económicos a sus familiares para que puedan iniciar con el proceso de repatriación, ${ }^{20}$ etc.; pero lo más grave es poder determinar responsabilidades frente a estos cadáveres que mueren a causa de la explotación y la desatención de los Estados.

Philip Zimbardo desagrega también la palabra "deshumanización" y analiza que deshumanizar a alguien es despojar a las personas de su humanidad y clasificarlas como "simples cosas". Además, constituye un proceso en donde el prejuicio, el racismo y la discriminación estigmatizan a determinados cuerpos atribuyéndoles una identidad que carece de valor porque para el sistema es más fácil ser cruel con "objetos deshumanizados". ${ }^{21}$

Hoy en día, en pleno siglo XXI existen formas actuales de esclavitud. Los esclavistas modernos que explotan a las mujeres, especialmente a las que se ven obligadas a prostituirse, impiden a las mujeres concebir porque no quieren gastar dinero en mantener a niños inútiles. No hay razón para proteger a los nuevos esclavos de enfermedades o lesiones: la medicina cuesta dinero y es más barato dejarlos morir. No son tratados como humanos si no como esclavos. ${ }^{22}$

19. Giorgio Agamben, Lo que queda de Auschwitz: el archivo y el testigo. Homo sacer III (Valencia: PreTextos, 2002), 84-6.

20. Gestión de protección a ecuatorianos en el exterior por repatriación de cadáveres o traslado de restos mortales del Ministerio de Relaciones Exteriores y Movilidad Humana del Ecuador para el 2021.

21. Philip G. Zimbardo, El efecto Lucifer (Barcelona: Paidós, 2012), 132-6.

22. Kevin Bales, Disposable People: New Slavery in the Global Economy, Rev. ed. (Berkeley: University of California Press, 2012), 15. 
Para Chimamanda Ngozi Adichie existen dos escenarios que se desprenden después de haber sido víctima y haber sido atravesada por varias condiciones como ser mujer y migrante: "ya no es la misma que fue, ahora se enfrenta con impaciencia a las penurias y corruptelas de su país y será observada por sus compatriotas con cierta desconfianza". ${ }^{23}$ Esta sensación desencadena tristeza y desesperación, por cuanto ellas han estado anhelando volver a sus hogares, con sus familias, y, al conseguirlo finalmente, sienten que ese anhelo no es lo que ellas esperaban.

Jean-Luc Nancy señala que cuando partimos de un lugar no necesariamente es porque actuamos mal en ese lugar sino porque percibimos a esa realidad ajena a nosotros. Esa realidad nos excluye. Incluso puede ser un modo de castigarnos el sentir que ese sitio ya no forma parte de nosotros. El principal aspecto ya no es descifrar si nos resulta placentero estar en ese lugar o no, sino que probablemente ya no tenemos el derecho de estar allí. ${ }^{24}$ Ciertamente las víctimas de trata de personas perciben esa no pertenencia porque permanecieron en constantes flujos de movimiento bajo coerción y violencia durante largos períodos de tiempo en espacios que Marc Augé denomina "no lugares".

Los no lugares refieren a las instalaciones necesarias para la circulación acelerada de personas que no reflejan ni tiempo ni lugar exacto, esto es: las rutas rápidas, los medios de transporte aéreos, terrestres, marítimos, incluso los campos de tránsito prolongado como los aeropuertos. ${ }^{25}$ Esta no pertenencia hace muchas veces que las víctimas, a pesar de iniciar los procesos de rehabilitación y recuperación, recaigan en varios momentos en la explotación sexual y contacten con las redes de trata de personas viendo a esa experiencia como propia y a la violencia que generan los tratantes como algo natural. ${ }^{26}$

\section{LOS ESTADOS COMO GENERADORES DE VIOLENCIA}

Desde la óptica de René Girard, en un estudio antropológico en relación a la dinámica en la que se desenvuelve la violencia, constantemente se busca y se identifica a una víctima sacrificial a quien se le descargarán todos los problemas y las desdichas

23. Chimamanda Ngozi Adichie, Americanah (Bogotá: Literatura Random House, 2018), 11.

24. Jean-Luc Nancy, ¿Qué significa partir? (Buenos Aires: Capital Intelectual, 2016), 18.

25. Marc Augé y Margarita Mizraji, Los "no lugares" espacios del anonimato una antropología de la sobremodernidad (Barcelona: Gedisa, 2008), 41.

26. Inmaculada Antolínez Domínguez y Esperanza Jorge Barbuzano, "Repensando la categoría de 'víctima': un análisis sobre la capacidad de agencia de mujeres migrantes vinculadas a redes de trata", Hachetetepé. Revista científica de educación y comunicación 2, n. ${ }^{\circ} 15$ (2017): 44-5, doi:10.25267/Hachetetepe.2017. v2.i15.5. 
que enfrenta el colectivo social. ${ }^{27}$ Esta víctima sacrificial no tiene valor, no merece un trato igual que los demás miembros del colectivo social, por cuanto, a causa del resultado de estas supuestas infracciones sociales, es menester que sea incluso eliminada al ser la generadora del caos.

Girard reflexiona también señalando que existen intereses detrás de las víctimas sacrificiales, quienes funcionan como cortinas de humo que pretenden desviar la atención sobre lo que realmente ocurre dentro del colectivo social. ¿Qué se quiere ocultar del ojo público? Existe entonces aquello que Ileana Diéguez señala como lo "impresentable" para el Estado. Estos escenarios que no pueden ser presentados públicamente deben ser silenciados y censurados. ${ }^{28}$

Generalmente, los problemas de fondo de una sociedad se deben a la inoperancia y mal funcionamiento del órgano que controla y regula esa sociedad, es decir el Estado. La violencia institucionalizada ejercida por el Estado busca con frecuencia a estas víctimas sacrificiales para quienes ni la dignidad ni el derecho les alcanza así como tampoco les protege. Para Claudio Nash Rojas, es común que estos conflictos se produzcan entre los estados y los particulares, pero no por ello se deben subestimar los intentos de los estados denunciados ante los organismos de justicia internacional por acallar justamente la protección internacional. ${ }^{29}$

En este sentido, para ejemplificar esta constante descarga de responsabilidades sobre las víctimas sacrificiales, me referiré a dos colectivos sociales: los migrantes irregulares y las mujeres víctimas de trata de personas. Las organizaciones criminales dedicadas a la trata de personas, el crimen organizado, el narcotráfico, el comercio ilegal de armas, la delincuencia organizada, el tráfico ilícito de migrantes, entre otros, han tomado diferentes modalidades y distintos estilos de operación en los últimos años. El comercio de seres humanos no es un negocio uniforme ni puede mirarse como una sola dinámica; por el contrario, actualmente opera de forma muy flexible y es capaz de desenvolverse en diversos contextos culturales y políticos.

El "bienestar colectivo, el progreso y la constante necesidad de activar la economía" son las estrategias comunicacionales que constantemente emplean los gobiernos frente a sus gobernados para justificar su accionar y ocultar sus verdaderos intereses. Para Yuval Noah Harari, el relato del progreso no es un relato convincente, es una idea obsoleta que se llegó para quedarse desde el advenimiento de la modernidad. La

27. René Girard, La violencia y lo sagrado (Barcelona: Anagrama, 2016), 15-6.

28. Ileana Diéguez Caballero, Cuerpos sin duelo: iconografías y teatralidades del dolor, $2013,50$.

29. Claudio Nash Rojas, "La eficacia del Sistema Interamericano de Derechos Humanos en tiempo de cólera", Revista Tribuna Internacional (2020): 22. 
idea de progreso nace en la premisa de que las cosas mejorarán si admitimos nuestra ignorancia y si usamos recursos en la investigación.

Esta idea se extendió hacia la economía, por eso se expandió el imaginario de que quienes crean los inventos tecnológicos y las mejoras en la organización social, aumentarán la producción, el comercio y la riqueza de los seres humanos. ${ }^{30}$ Constantemente los estados desencadenan también violencia sobre ciertos cuerpos, bajo esta idea caduca del progreso, y responden a las empresas nacionales e internacionales y a ciertos grupos de poder que están involucrados en la trata de personas.

En este sistema capitalista, agresivo y eminentemente neoliberal la trata de personas y el tráfico ilícito de migrantes, desde la óptica capitalista, activan los flujos económicos dentro y fuera de las fronteras de los países. A menudo, estos dos delitos son confundidos por estar relacionados con el traslado de personas, pero son prácticas delictivas completamente distintas. Para Soledad Álvarez, existen decisiones con criterios contrarios tomadas e impuestas por los estados. Las políticas estatales orientadas al control fronterizo, traslado de personas y control migratorio cada día adquieren más fuerza y son aplicadas con mucho rigor, sin embargo, diariamente se reportan flujos migratorios irregulares.

En este sentido, por más regular e institucional que sea, el aparente control aplicado por la fuerza pública, en su mecanismo, es un "contraderecho", ${ }^{31}$ porque, por un lado, controla cuerpos para presuntamente protegerlos, pero, por otro, los explota.

La autora señala que a primera vista lo que parece una simple contradicción revela contrariamente un aspecto del capitalismo contemporáneo denominado: "la exclusión a través de la inclusión", que constituye el mecanismo por el cual la "fuerza de trabajo" de los migrantes, y en este caso las víctimas de trata con fines de explotación sexual, es tradicionalmente poco calificada y proveniente de países pobres, y está destinada a la irregularidad y es agregada bajo esa condición, es decir, como fuerza de trabajo irregular, barata, y desechable.$^{32}$ Los nuevos esclavos no son una inversión a largo plazo. A diferencia de las formas antiguas de esclavitud, son baratos, requieren poco cuidado y son desechables. ${ }^{33}$

30. Yuval Noah Harari, Sapiens. De animales a dioses: una breve historia de la humanidad (Buenos Aires: Titivillus, 2019), 431.

31. Michel Foucault, Vigilar y castigar: nacimiento de la prisión (Buenos Aires: Siglo XXI, 2004), 206.

32. Soledad Álvarez Velasco, “¿Crisis migratoria contemporánea? Complejizando dos corredores migratorios globales", Revista Ecuador Debate, n. ${ }^{\circ} 97$ (2016): 158-9.

33. Bales, Disposable People, 15-6. 


\section{EL VÍNCULO DEL PATRIARCALISMO CON LAS MUJERES VÍCTIMAS DE TRATA DE PERSONAS}

En el Reporte Global de la Oficina de Naciones Unidas contra la Droga y el Delito, UNODC, se identifica que "las 2 terceras partes de las víctimas de trata de personas detectadas por las autoridades son mujeres y el $79 \%$ de ellas sometidas a explotación sexual". ${ }^{34}$ Según este mismo reporte "el $66 \%$ de las víctimas de trata de personas identificadas desde 2006 en países de América Latina son mujeres y el 13\% de ellas son niñas". ${ }^{35}$

Debido a las altas cifras indicadas por el UNDOC, es necesario vincular la trata de personas como un delito cuyo fin es la constante búsqueda de mujeres para someterlas a condiciones de explotación sexual. Para la UNDOC existen cuatro principales causas para abordar la trata de personas con un enfoque de género. Estas causas son: 1) La desigualdad de género: atravesada por problemáticas que comprenden la pobreza de género, la falta de oportunidades viables de empleo, la falta de control sobre los recursos financieros y el acceso limitado a la educación son factores potencian la vulnerabilidad de las mujeres y las niñas a la trata;36 2 ) La violencia de género: históricamente reproducida como una práctica cultural que ha normalizado dicha violencia contribuye al ciclo repetitivo de violencia contra las mujeres y las niñas que las expone a ser potenciales víctimas de trata; ${ }^{37} 3$ ) Legislaciones discriminatorias de trabajo o migración y políticas públicas ciegas ante el género: la normativa laboral y migratoria que carece de un enfoque de derechos humanos y sensibilidad al género restringe la capacidad de las mujeres para transitar libremente y cambiar de empleo, esto incrementa las probabilidades de búsqueda de empleos en sectores no regulados e informales. ${ }^{38}$ Consecuentemente, esto aumenta la vulnerabilidad de las mujeres a la trata con fines de explotación sexual; 4) Conflictos, escenarios posteriores a conflictos y crisis humanitarias: con las crisis sociales, económicas y humanitarias las mujeres y las niñas pueden volverse altamente vulnerables a las diferentes formas de explotación, especialmente en escenarios en donde se desenvuelven grupos armados

34. Oficina de las Naciones Unidas contra la Droga y el Delito, UNODC, "Algunos datos relevantes sobre la trata de personas" (Viena, 2009), 1.

35. Ibíd., 1-2.

36. Oficina de las Naciones Unidas contra la Droga y el Delito, UNODC, "Las dimensiones de género de la trata de personas" (Viena: Grupo de Coordinación Interinstitucional UNODC, 2017), 1-2.

37. Oficina de las Naciones Unidas contra la Droga y el Delito, UNODC, "Algunos datos relevantes sobre la trata de personas", 1-2.

38. Oficina de las Naciones Unidas contra la Droga y el Delito, UNODC, "Las dimensiones de género de la trata de personas", 1-2. 
que atacan a las mujeres y las niñas para someterlas a esclavitud sexual, servidumbre doméstica y matrimonios forzados. ${ }^{39}$

En virtud de que las mujeres constituyen el grupo humano más vulnerable de ser captado por las redes de trata de personas, la normativa internacional ha aterrizado esta realidad hacia algunos instrumentos internacionales entre los que se destaca esta necesidad especial de protección a las mujeres. El artículo 6 de la Convención sobre la eliminación de todas las formas de discriminación contra la mujer impulsa a los estados parte a "tomar todas las medidas apropiadas, incluida la legislación, para reprimir todas las formas de trata de mujeres y la explotación de la prostitución de mujeres". ${ }^{40}$

La Declaración sobre la Eliminación de la Violencia contra la Mujer define la violencia contra la mujer como:

Todo acto de violencia sexual que tenga o pueda tener como resultado un daño o sufrimiento físico, sexual o psicológico para la mujer, así como las amenazas de tales actos, la coacción o la privación arbitraria de la libertad, tanto si se producen en la vida pública como en la vida privada, e incluida la violencia doméstica, los delitos cometidos por cuestiones de honor, los crímenes pasionales, las prácticas tradicionales nocivas para la mujer, incluida la mutilación genital femenina y el matrimonio forzado. ${ }^{41}$

Por otra parte, los hombres como consumidores tradicionales que generan violencia eminentemente patriarcal y en donde el Estado, a través de sus funcionarios de control que consumen el mercado de trata, interviene también como protagonista de consumo de mujeres víctimas de trata de personas en los burdeles, son quienes miran a los burdeles como motivación de visita, en la que el fin principal no es la búsqueda de satisfacción sexual, sino de la celebración de acuerdos, alianzas, negocios, pactos de masculinidad que buscan el reconocimiento del poder de ellos sobre los cuerpos de las mujeres. Pactos que cuentan con todo tipo de perfiles como jueces, policías y cuadros políticos. ${ }^{42}$

Esta constante mutación que van adquiriendo las nuevas formas de violencia, en el contexto de las víctimas de trata de personas, transmite un mensaje de impunidad y expresa justamente este poder de dominio y captura sobre cuerpos y territorios. Para Rita Segato, en estas nuevas formas de violencia, los cuerpos de las mujeres

39. Ibíd.

40. Convención sobre la eliminación de todas las formas de discriminación contra la mujer, Estados Unidos, 1979, art. 6.

41. Declaración sobre la eliminación de la violencia contra la mujer, Ginebra, 1993, art. 3.

42. Rita Laura Segato, Las nuevas formas de la guerra y el cuerpo de las mujeres (Ciudad de México: Tinta Limón, 2013), 110. 
funcionan a modo de lienzos, bastidores, incluso como territorios para establecer los términos de la contienda protagonizada por quienes generan esta violencia. ${ }^{43}$

Para Segato, un ejemplo claro de esta corrupción dada entre los tratantes y los funcionarios públicos se traduce en las coimas que se entregan a la policía para que esta no clausure ni cierre los burdeles, sitios frecuentados por los mismos miembros policiales o de funcionarios que trabajan para otras instituciones del gobierno. En su texto "Nuevas formas de la guerra y el cuerpo de las mujeres", señala:

He sabido de un comisario de los alrededores de La Plata a quien, por no aceptar la explotación de niñas paraguayas en un burdel de su distrito, le fueron ofrecidas dos opciones: o pasar a retiro prematuramente o ser trasladado a un municipio bonaerense remoto y de importancia menor. La orden vino directamente de un funcionario de gobierno por motivo de la disminución de la colecta para la caja electoral. ${ }^{44}$

Es importante destacar que estas redes criminales son horizontales y descentralizadas, su flexibilidad permite la cooperación con otros grupos delictivos para generar respuestas rápidas frente a la actividad policial y con ello evadir los controles y los operativos constantes. Estas nuevas modalidades que presenta la trata de personas actualmente pretende impulsar cambios legislativos, así como mutar adaptándose a la oferta y la demanda en los mercados nacionales e internacionales ${ }^{45}$ en donde se comercializan incluso los cuerpos.

Como se ha explicado en líneas anteriores, la violencia que se ejerce sobre ciertos cuerpos, y principalmente sobre los cuerpos de las mujeres, proviene de ambas direcciones en donde también tienen un grado de responsabilidad los estados. Katharine Bartlett señala que la violencia de las mujeres no se muestra como es realmente, solo se la estudia de forma un tanto superficial que no expone a profundidad el sufrimiento real que genera sobre las mujeres, y señala:

Las mujeres saben que el mundo está ahí afuera porque nos golpea en la cara. Literalmente. Somos violadas, maltratadas, pornografiadas, definidas por fuerza, por un mundo que se inicia, por lo menos, enteramente fuera de nosotras. El mundo se mantiene real 'sin importar qué pensemos acerca de él' ${ }^{46}$

43. Ibíd., 6-8.

44. Ibíd., 109 .

45. Aronowitz, Theuermann y Tyurykanova, Analysing the Business Model of Trafficking in Human Beings to Better Prevent the Crime.

46. Marisol Fernández, Félix Morales y Katharine T. Bartlett, eds., Métodos feministas en el derecho: aproximaciones críticas a la jurisprudencia peruana (Lima: Palestra, 2011), 91. 
Finalmente, Segato ha señalado que las mujeres víctimas de explotación sexual generada por la trata de personas pueden ser víctimas a su vez de violencia institucionalizada aplicada directa o indirectamente por los estados. Desde el punto de vista de Segato, la trata de personas con fines de explotación sexual ejercida principalmente hacia el colectivo humano "mujeres" guarda similitud con los delitos considerados por el corpus iuris internacional como delitos de genocidio ${ }^{47}$ y lesa humanidad. ${ }^{48}$

Desde luego, este es un análisis únicamente comparativo que realiza la autora en virtud de dimensionar la magnitud de las violaciones a los derechos humanos producto de la trata de personas, mas no constituye un análisis desde la esfera jurídica-penal tendiente a analizar si el femigenocidio cumple o no con los estándares materiales y formales normativos establecidos por la técnica legislativa para ser considerado un delito. El sometimiento a condiciones infrahumanas tales como la reducción a condiciones de esclavitud, concentracionistas, el abandono, la desnutrición de sus bebés de sexo femenino, constituye un tipo de feminicidio. Segato define el femigenocidio como:

El femigenocidio se aproxima a la categoría de genocidio por sus agresiones a mujeres con intención de letalidad y deterioro físico en contextos de impersonalidad, en las cuales los agresores son un colectivo organizado o, mejor dicho, son agresores porque forman parte de un colectivo o corporación y actúan mancomunadamente, y las víctimas también son víctimas porque pertenecen a un colectivo en el sentido de una categoría social, en este caso, de género. ${ }^{49}$

En este análisis la autora invita a reflexionar el nivel de responsabilidad que tienen los estados frente a la violencia ejercida por los tratantes y cómo los delitos aparentemente ejercidos de forma individual afectan de forma colectiva a grupos humanos históricamente discriminados, como son las mujeres.

Por su parte, la Corte Constitucional del Ecuador ha creado jurisprudencia con relación a este aspecto en la sentencia n. $.^{\circ} 388-16-E P / 21$, mediante la cual señala que en esa pérdida de espacialidad y despojo constante de cuerpos y lugares que se producen en estos flujos migratorios y de constante movimiento también se vulneran los derechos a la identidad ${ }^{50}$ de las víctimas que quedan imposibilitadas de realizar actos que las personas que ejercen sus derechos plenamente pueden hacerlo.

47. Estatuto de Roma de la Corte Penal Internacional, Países Bajos, 1 de julio de 2002, art. 6.

48. Ibíd., art. 7.

49. Rita Laura Segato, La guerra contra las mujeres, Mapas 45 (Madrid: Traficantes de Sueños, 2016), 85, https://bit.ly/36V8KAA.

50. Corte Constitucional Ecuador, Sentencia n. ${ }^{\circ}$ 388-16-EP/21, 23 de junio de 2021. 
La letra $\mathrm{b}$ del artículo 1 de la Convención Interamericana para prevenir, sancionar y erradicar la violencia contra la mujer "Convención de Belem Do Pará", en el contexto de violencia física, sexual o psicológica en contra de la mujer, señala:

b. Que tenga lugar en la comunidad y sea perpetrada por cualquier persona y que comprende, entre otros, violación, abuso sexual, tortura, trata de personas, prostitución forzada, secuestro y acoso sexual en el lugar de trabajo, así como en instituciones educativas, establecimientos de salud o cualquier otro lugar. ${ }^{51}$

La trata de personas con fines de explotación sexual guarda profunda relación con el mercado capitalista, por cuanto debe ser analizada desde el punto de vista económico. Es importante analizar la intocabilidad que tienen los estados para blindarse respecto a la trata de personas que sigue siendo un crimen del cual uno de los responsables es el Estado. Bajo la lógica de los flujos económicos y la valoración de los cuerpos, que se analizó en líneas precedentes en función del capital, el cuerpo femenino ha sido capitalizado con bajísimos niveles de inversión, lo que puede considerarse una especie de renta derivada de la explotación de un territorio-cuerpo que ha sido apropiado por alguien, lo que la autora denomina en términos económicos la "acumulación por desposesión". 52

La pedagogía de la crueldad que promueve y naturaliza el espectáculo del desecho ya que el cuerpo de las mujeres es visto como un objeto de consumo, por ende, tendrá un tiempo de útil de uso lo que propaga la idea del goce como secuencia de consumo $\mathrm{y}$ desecho, ${ }^{53} \mathrm{y}$ las condiciones de esclavitud a las que son reducidas las mujeres. Estas estrategias concentracionistas, el abandono y la subnutrición de bebés de sexo femenino constituyen también un tipo de feminicidio, puesto que la violencia se origina justamente hacia un colectivo social, las mujeres configurándose con esto una muestra más del patriarcalismo. ${ }^{54}$

El Estado constantemente juega un doble papel dependiendo de los cuerpos, en función de su tipología, por un lado, protege unos cuerpos y, por otro, segrega y elimina a otros. Excluye a través de la inclusión ${ }^{55}$ bajo las exigencias del mercado, una

51. Convención Interamericana para Prevenir, Sancionar y Erradicar la Violencia contra la Mujer. Convención de Belem Do Para, Belem do Para Brasil, 9 de junio de 1994, art. 1.

52. Segato, Las nuevas formas de la guerra y el cuerpo de las mujeres, 108-10.

53. Rita Laura Segato, Las estructuras elementales de la violencia: ensayos sobre género entre la antropología, el psicoanálisis y los derechos humanos, Derechos humanos. Viejos problemas, nuevas miradas (Buenos Aires: Universidad Nacional de Quilmes / Prometeo 3010, 2003), 76.

54. Segato, La guerra contra las mujeres, 85 .

55. Álvarez Velasco, “¿Crisis migratoria contemporánea? Complejizando dos corredores migratorios globales", 158-9. 
vez más del sistema capitalista. Para el jurista y sociólogo Erick Olin Wright, un parámetro importante para poder identificar estas prácticas y determinar a quién realmente benefician las políticas estatales es a través de la aplicación del método de la brújula. La brújula socialista permitirá identificar si las políticas públicas se están tomando en observancia de la dirección adecuada. ${ }^{56}$

Este método constituye una alternativa que invita a preguntarse a qué estamento las políticas estatales benefician: al Estado, a las empresas o al pueblo. No existe un momento que no llegue sin su oportunidad revolucionaria. ${ }^{57}$ Según lo señalado por Wright, se puede confirmar que las políticas estatales empleadas sobre los cuerpos víctimas de trata de personas benefician a las empresas que promueven el mercado y la activación de flujos del capital, son a quienes los estados revisten contrariamente de "legalidad" pero que podrían haber acomodado el camino para el cometimiento de prácticas delictivas y que son ejecutadas por funcionarios públicos para que puedan desenvolverse con "regularidad" y así, por ejemplo, sigan activando la economía.

Para Louise Shelley, existen tres categorías importantes desde las cuales se debe analizar la trata de personas: En primer lugar, la perspectiva de género, en segundo lugar, la perspectiva de derechos humanos; $\mathrm{y}$, finalmente, la perspectiva impulsada por el mercado. ${ }^{58}$ En este contexto tomaré la perspectiva impulsada por el mercado para vincularla en un inicio con la trata de personas como un negocio del capitalismo. Shelley ha destacado seis categorías de grupos traficantes y sus modalidades de negocios.

El primer modelo denominado "Modelo de recursos naturales o crimen organizado postsoviético" que está dedicado a la venta de las mujeres dentro del comercio de recursos madereros o de las pieles de animales. Este negocio refleja la prerrevolución del comercio ruso de recursos naturales y el nuevo énfasis ruso en la venta de petróleo y gas, en el que también están involucradas las mujeres víctimas de trata de personas. ${ }^{59}$

El segundo modelo denominado "Modelo de comercio y desarrollo: traficantes y tratantes chinos" es un modelo enfocado en la captación de víctimas hombres para fines explotarlos en el ámbito laboral, sin embargo, también se ha identificado la existencia de trata de mujeres, quienes representan el diez por ciento del comercio total de personas. Las operaciones relacionadas en las que se identificó la existencia de trata

56. Erick Olin Wright, "Los puntos de la brújula. Hacia una alternativa socialista”, New Left Review, n. ${ }^{\circ} 41$ (2006): 91.

57. Walter Benjamin, "Tesis sobre la historia y otros fragmentos", 1989, 39, tesis XVIIa.

58. Louise Shelley, "Trafficking in Women: The Business Model Approach", The Brown Journal of World Affairs, 10 (2021): 119.

59. Ibíd., 124. 
es contrabando en todas las etapas, desde el reclutamiento, la servidumbre por deudas y finalmente una asignación de víctimas en burdeles. ${ }^{60}$

El tercer modelo denominado "Modelo de supermercado: bajo costo y alto índice comercial entre EE.UU. y México" es un modelo tradicionalmente practicado, se relaciona directamente con el contrabando transfronterizo de bajo costo que se ha caracterizado en la frontera entre Estados Unidos y México por más de un siglo. En esta sociedad de consumo atravesada por la dinámica utilitarista, dentro de estos dos escenarios Bauman identifica a dos tipos de consumidores turistas y vagabundos, pero los segundos son consumidores defectuosos. ${ }^{61}$

Con mucha y casi absoluta dificultad los vagabundos podrán estar en la misma posición que un turista y activar los flujos económicos de consumo que solo el dinero puede lograrlo, entonces su situación se restringe a la marginalidad y a la segregación porque no poseen los medios suficientes para ubicarse en la categoría de turista en un lugar que originariamente no es el suyo; por ello, fácilmente se encuentran en condiciones vulnerables para ser captados por las redes de trata.

El cuarto modelo denominado "Modelo de emprendedor violento: Balkan Crime Gr" está enfocado en la captación de mujeres para someterlas a la trata, identificando principalmente a mujeres provenientes de los Balcanes que son vendidas a comerciantes balcánicos por grupos delictivos de la antigua Unión Soviética y Europa del Este. ${ }^{62}$ Es un modelo oportunista tanto en los países de origen como en los receptores. La inestabilidad y el conflicto civil en la región de origen proporcionan un gran número de mujeres que son vulnerables a la trata. ${ }^{63}$

Para Elizabeth Odio, otras formas de violencia ejercida por los estados orientada justamente hacia las mujeres se produce también cuando son obligadas a concebir. Para ejemplificar, Odio explica que, incluso en el contexto de guerra, desde 1988 las mujeres migrantes musulmanas eran comúnmente violadas por soldados serbios que las embarazaban forzadamente con el afán de utilizarlas como armas de guerra y a modo de exterminio contra sus grupos enemigos. ${ }^{64}$

El quinto modelo denominado "Modelo de Esclavitud tradicional con tecnología moderna: Nigeria y África Occidental" es un modelo que está relacionado con la

60. Ibíd., 125 .

61. Zygmund Bauman, “Turistas y vagabundos”, en La globalización. Consecuencias humanas (Ciudad de México: Fondo de Cultura Económica / Centro de Investigación y Docencia Económica, 1999), 14-5.

62. Shelley, "Trafficking in Women: The Business Model Approach", 126.

63. Ibíd.

64. Elizabeth Odio Benito, "La perspectiva y el mandato de género en el Estatuto de Roma", Revista IIDH/ Instituto Interamericano de Derechos Humanos, n. ${ }^{\circ} 59$ (junio 2014): 257. 
esclavitud del pasado, con las comunidades y tribus locales involucradas en el reclutamiento.

Finalmente, el sexto modelo denominado "Modelo de actor racional con enfoque de regulación holandés" está direccionado al control de la trata en un país receptor. Caracterizado por ser en un modelo regulatorio que se aplica a otros negocios legítimos. La eficacia de este modelo se basa en la legalización de la prostitución y el mantenimiento de burdeles.$^{65}$ Este es el modelo que emplean los estados para confundir la prostitución con la trata de personas y así blindar la trata como una práctica que aparentemente goza de plena legalidad.

Para Claudia Storini, esta distinción entre la prostitución y la trata de personas se hizo visible por primera vez en Europa con la entrada en vigor de la Convención Internacional para la Represión de la Trata de Mujeres Mayores de Edad en 1993, en la que los estados tienen la obligación de monitorear y controlar la prostitución voluntaria e involuntaria con el propósito de considerar la prostitución como una práctica incompatible con la dignidad humana. ${ }^{66}$ A pesar de que esta aclaración se hizo a través de un instrumento jurídico válido hace más de dos décadas, se puede destacar que esta confusión permanece hasta la actualidad, como se ha indicado en líneas precedentes.

A los gobiernos no les interesa perseguir a estas redes criminales de forma adecuada porque son estas mismas prácticas las que mueven grandes cantidades de dinero y sobre las cuales desafortunadamente se encuentran nuevamente los cuerpos de las mujeres como instrumentos para ejercer esta violencia. Las inacciones de los gobiernos generan también responsabilidades en todos los niveles puesto que sus inacciones generan también niveles de incumplimiento.

$\mathrm{Al}$ respecto, dentro del contexto de las víctimas de trata de personas y las obligaciones nacionales e internacionales que tienen los estados, la Corte Interamericana de Derechos Humanos en el caso Hacienda Brasil Verde vs. Brasil condenó al Estado por violar la prohibición de esclavitud contemplada en el artículo 6 de la Convención Americana de Derechos Humanos, ${ }^{67}$ y en su argumentación desarrolló la categoría de discriminación estructural histórica. ${ }^{68}$ Por ello, los Estados deben observar la dimensión que tienen los efectos de las políticas públicas que dictan.

65. Shelley, "Trafficking in Women: The Business Model Approach", 123-9.

66. Claudia Storini, "Trata de seres humanos y tráfico de inmigrantes en los albores del siglo XXI", s. f., 1789.

67. Convención Americana sobre Derechos Humanos, Costa Rica, art. 6.

68. Corte Interamericana de Derechos Humanos, Sentencia Caso Trabajadores de la Hacienda Brasil Verde vs. Brasil, 20 de octubre de 2016, serie $\mathrm{C} \mathrm{n}^{\circ}{ }^{\circ}$ 318, párr. 343. Washington. 
Los estados como estructuras de poder que controlan y regulan a los colectivos sociales tienen la obligación de respetar, proteger, garantizar y promover los derechos humanos de las personas; ${ }^{69}$ por otro lado, está su obligación de aplicar su poder punitivo sobre las conductas socialmente lesivas, es decir el cometimiento de delitos como la trata de personas. En esta línea, del respeto y el cabal cumplimiento a los derechos humanos, es necesario que se cree toda la maquinaria institucional indispensable para la realización de los derechos humanos, creando a su vez la infraestructura legal e institucional de la que dependen la realización práctica de los derechos, así como también la obligación de repararlos en caso de determinarse su vulneración.

\section{CONCLUSIONES}

Frente a la determinación del valor de unos cuerpos sobre otros, en virtud de la deshumanización que enfrenta nuestra sociedad a causa del sistema capitalista, este ha convertido a ciertos sujetos en objetos de consumo. Las mujeres víctimas de trata de personas son sometidas a condiciones de explotación en varios niveles, por cuanto tienen mucha restricción para acceder a sus derechos y por ende se cuestiona su humanidad desde el análisis del valor de los cuerpos y el ejercicio de sus derechos.

La valoración de unos cuerpos sobre otros también se determina en función de la producción económica capitalista, generada por las empresas y aplicada por los estados. Debido a que es necesario incrementar las ganancias, y que los flujos comerciales nacionales e internacionales sean cada vez más baratos para los productores, se han desarrollado formas modernas de esclavitud, de las que se destaca la explotación a los cuerpos de las mujeres con el delito de trata de personas con fines de explotación sexual.

Los estados cumplen un rol fundamental como garantes de derechos, pero también como responsables por las vulneraciones de derechos de las mujeres víctimas de trata de personas al institucionalizar la violencia. El patriarcalismo como una práctica cultural reproducida a través del tiempo coloca a las mujeres como potenciales víctimas de trata de personas con fines de explotación sexual, al ser el colectivo humano con el porcentaje mayor de víctimas de trata reportado cada año. El cuerpo femenino ha sido capitalizado, discriminado y explotado de forma sistémica.

Finalmente, a pesar de la existencia de normativa nacional e internacional que protege a las mujeres víctimas de este delito, hacen falta grandes esfuerzos y compro-

69. Servicio Profesional en Derechos Humanos, Fundamentos Teóricos de los Derechos Humanos (Ciudad de México: Comisión de Derechos Humanos del Distrito Federal, 2011), 39-43, https://bit.ly/2Tt9tWv. 
misos que los estados deben asumir para poder reducir y erradicar la trata de personas a nivel mundial.

\section{BIBLIOGRAFÍA}

Adichie, Chimamanda Ngozi, y Elvira Lindo. Americanah. Bogotá: Literatura Random House, 2018.

Agamben, Giorgio. Lo que queda de Auschwitz: el archivo y el testigo. Homo sacer III. Valencia: Pre-Textos, 2002.

Álvarez Velasco, Soledad. “CCrisis migratoria contemporánea? Complejizando dos corredores migratorios globales”. Revista Ecuador Debate, n. 97 (2016): 155-71.

Antolínez Domínguez, Inmaculada, y Esperanza Jorge Barbuzano. "Repensando la categoría de 'víctima': un análisis sobre la capacidad de agencia de mujeres migrantes vinculadas a redes de trata". Hachetetepé. Revista cientifica de educación y comunicación 2, n. ${ }^{\circ} 15$ (2017): 37-49. doi:10.25267/Hachetetepe.2017.v2.i15.5.

Aronowitz, Alexis A., Gerda Theuermann y Elena Tyurykanova. Analysing the Business Model of Trafficking in Human Beings to Better Prevent the Crime. Vienna: OSCE Office to the Special Representative and Co-ordinator for Combating Trafficking in Human Beings, 2010.

Augé, Marc, y Margarita Mizraji. Los "no lugares” espacios del anonimato una antropología de la sobremodernidad. Barcelona: Gedisa, 2008.

Bales, Kevin. Disposable People: New Slavery in the Global Economy. Rev. ed. Berkeley: University of California Press, 2012.

Bauman, Zygmund. "Turistas y vagabundos". En La globalización. Consecuencias humanas, 103-33. Ciudad de México: Fondo de Cultura Económica / Centro de Investigación y Docencia Económica, 1999.

Benjamin, Walter. "Tesis sobre la historia y otros fragmentos", 1989, 75.

Convención Americana sobre Derechos Humanos. Convenio 36 de la Organización de Estados Americanos. Costa Rica, 22 de noviembre de 1969.

Convención de las Naciones Unidas contra la delincuencia organizada transnacional y sus protocolos. 2004.

Convención Interamericana para Prevenir, Sancionar y Erradicar la Violencia contra la Mujer. Convención de Belem Do Para. 9 de junio de 1994.

Convención sobre la eliminación de todas las formas de discriminación contra la mujer. Estados Unidos, 1979.

Corte Interamericana de Derechos Humanos. Sentencia Caso Trabajadores de la Hacienda Brasil Verde vs. Brasil. Washington D. C., 20 de octubre de 2016.

Declaración sobre la eliminación de la violencia contra la mujer. Ginebra, 1993.

Diéguez Caballero, Ileana. Cuerpos sin duelo: iconografias y teatralidades del dolor. 2013.

Ecuador. Código Orgánico Integral Penal. Registro Oficial 180, 10 de febrero de 2014. 
-. Constitución de la República del Ecuador. Registro Oficial 449, 20 de octubre de 2008.

- Ley Orgánica de Movilidad Humana. Registro Oficial 938, 6 de febrero de 2017.

Ecuador, Corte Constitucional. Sentencia n. ${ }^{\circ}$ 388-16-EP/21. 23 de junio de 2021.

Estatuto de Roma de la Corte Penal Internacional. Países Bajos, 1 de julio de 2002.

Fernández, Marisol, Félix Morales y Katharine T. Bartlett, editores. Métodos feministas en el derecho: aproximaciones criticas a la jurisprudencia peruana. Lima: Palestra, 2011.

Foucault, Michel. Vigilar y castigar: el nacimiento de la prisión. Buenos Aires: Siglo XXI, 2004.

Girard, René. La violencia y lo sagrado. Barcelona: Anagrama, 2016.

Harari, Yuval Noah. Sapiens. De animales a dioses: una breve historia de la humanidad. Buenos Aires: Titivillus, 2019.

Nancy, Jean-Luc. ¿Qué significa partir? Buenos Aires: Capital Intelectual, 2016.

Odio Benito, Elizabeth. "La perspectiva y el mandato de género en el Estatuto de Roma". Revista IIDH/Instituto Interamericano de Derechos Humanos, n. 59 (junio 2014): 344.

Oficina de las Naciones Unidas contra la Droga y el Delito, UNODC. "Algunos datos relevantes sobre la trata de personas". Viena, 2009.

—. "Las dimensiones de género de la trata de personas". Viena: Grupo de Coordinación Interinstitucional UNODC, 2017.

Rojas, Claudio Nash. "La eficacia del Sistema Interamericano de Derechos Humanos en tiempo de cólera". Revista Tribuna Internacional (2020): 21.

Segato, Rita Laura. La guerra contra las mujeres. Mapas, 45. Madrid: Traficantes de Sueños, 2016. https://bit.ly/36V8KAA.

- Las estructuras elementales de la violencia: ensayos sobre género entre la antropología, el psicoanálisis y los derechos humanos. Derechos humanos. Viejos problemas, nuevas miradas. Buenos Aires: Universidad Nacional de Quilmes / Prometeo 3010, 2003.

- Las nuevas formas de la guerra y el cuerpo de las mujeres. Ciudad de México: Tinta Limón, 2013.

Servicio Profesional en Derechos Humanos. Fundamentos Teóricos de los Derechos Humanos. Ciudad de México: Comisión de Derechos Humanos del Distrito Federal, 2011. https://bit.ly/2Tt9tWv.

Shelley, Louise. "Trafficking in Women: The Business Model Approach", The Brown Journal of World Affairs, 10 (2021): 119-31.

Storini, Claudia. "Trata de seres humanos y tráfico de inmigrantes en los albores del siglo XXI", s. f., 24.

Women's Link Worldwide. Víctimas de Trata en América Latina. Entre la desprotección e indiferencia. Informe n. ${ }^{\circ}$ 7. Madrid, 2017. https://bit.ly/3zlkJU2.

Wright, Erick Olin. "Los puntos de la brújula. Hacia una alternativa socialista". New Left Review, n. ${ }^{\circ} 41$ (2006): 81-109.

Zimbardo, Philip G. El efecto Lucifer. Barcelona: Paidós, 2012. 